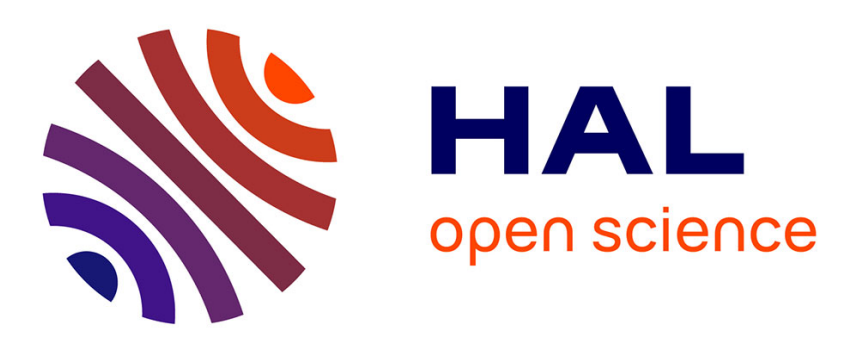

\title{
Insights on dispersal and recruitment paradigms: sex- and age-dependent variations in a nomadic breeder
}

Paul Acker, Charlotte Francesiaz, Arnaud Béchet, Nicolas Sadoul, Catherine Lessells, Agata Pijl, Aurélien Besnard

\section{- To cite this version:}

Paul Acker, Charlotte Francesiaz, Arnaud Béchet, Nicolas Sadoul, Catherine Lessells, et al.. Insights on dispersal and recruitment paradigms: sex- and age-dependent variations in a nomadic breeder. Oecologia, 2018, 186 (1), pp.85-97. hal-01939674

\section{HAL Id: hal-01939674 https://hal.science/hal-01939674}

Submitted on 29 Nov 2018

HAL is a multi-disciplinary open access archive for the deposit and dissemination of scientific research documents, whether they are published or not. The documents may come from teaching and research institutions in France or abroad, or from public or private research centers.
L'archive ouverte pluridisciplinaire HAL, est destinée au dépôt et à la diffusion de documents scientifiques de niveau recherche, publiés ou non, émanant des établissements d'enseignement et de recherche français ou étrangers, des laboratoires publics ou privés. 


\title{
Insights on dispersal and recruitment paradigms: sex- and age-dependent variations in a nomadic breeder
}

\author{
Paul Acker · Charlotte Francesiaz • Arnaud Béchet · Nicolas Sadoul • \\ Catherine M. Lessells · Agata S. Pijl • Aurélien Besnard
}

How to cite :

Acker P., Francesiaz C., Béchet A., Sadoul N., Lessells C.M., Pijl A.S., Besnard A. 2018. Insights on dispersal and recruitment

paradigms: sex- and age-dependent variations in a nomadic breeder. Oecologia 186:85-97. doi: 10.1007/s00442-017-3972-7

Electronic supplementary material The online version of this article (doi:10.1007/s00442-017-3972-7) contains supplementary material, which is available to authorized users.

\begin{abstract}
Sex- and age-dependence in recruitment and dispersal are often explained by costs arising from competition for holding a breeding territory over the years - a typical feature of species living in stable habitats. For instance, long-lived birds with male territoriality often exhibit large variation in recruitment age and higher dispersal in females and young individuals. As a corollary, we expected that species with ephemeral habitat suitability, and hence nomadic breeding, would show weak age- and sex-dependence in dispersal and low variation in recruitment age, because territory ownership is not maintained over the years. In addition, the higher cost of reproduction in females might not be (over)compensated for by costs of territoriality in males. Accordingly, females would recruit later than males. We explored these variations using multievent capture-recapture models over 13 years, 3479 (2392 sexed) slender-billed gulls (Chroicocephalus genei) and 45 colony sites along the French Mediterranean coast. As expected, variability in recruitment age was low with males recruiting earlier than females. Nonetheless, dispersal in and out of the study area decreased with age and was slightly higher in males than in females. Decreased dispersal with age might result from foraging benefits associated with increased spatial familiarity. Higher dispersal in males might be explained by a malebiased sex ratio or higher philopatry benefits in females (arising from their higher cost of reproduction). Sex- and age-dependent dispersal and recruitment may thus occur in the absence of year-to-year breeding territory ownership, which stresses the importance of considering other processes in shaping recruitment and dispersal patterns.
\end{abstract}

\section{Introduction}

When and where animals breed are 'two sides of the same coin' (Ens et al. 1995) that shape short- and long-term fitness prospects (Bowler and Benton 2005; Cam and Aubry 2011). Recruitment to a breeding population and dispersal are thus pivotal and intimately linked processes in life histories. They also have major consequences on population dynamics and gene flow (Charlesworth 1994; Bowler and Benton 2005).

Early recruitment should be selected when it maximizes the expected number of breeding attempts over the lifespan (Charlesworth 1994). However, delayed recruitment may be favoured when it limits the cost of first reproduction

(e.g., Desprez et al. 2014) and allows behavioural maturation (gains in competitive or foraging skills) to increase the chance of acquiring a breeding site of good quality and producing offspring (Charlesworth 1994; Aubry et al. 2009). Prospecting, competing, and queuing for good-quality sites may also result in recruitment delays (Ens et al. 1995; Boulinier and Danchin 1997).

Heterogeneity in individual tactics may yield substantial variations in recruitment age; this is commonly observed in most long-lived animals (e.g., birds: Becker and Bradley 2007; Aubry et al. 2009; mammals: Martin and FestaBianchet 2012; Desprez et al. 2014; reptiles: Congdon et al. 1993). The optimal recruitment age depends on individual competitive abilities and habitat quality (which may depend on density, food availability, etc.) and their interaction (birds: van de Pol et al. 2007; Aubry et al. 2009; mammals: Komers et al. 1997; Gaillard et al. 2000). In addition, due to asymmetric costs of reproduction (Clutton-Brock 1991; e.g., in birds: Williams 2005; mammals: Michener and Locklear 1990), sex differences in recruitment age might evolve through different optimal ages of behavioural maturity (Kim et al. 2011).

Dispersal is expected to be a response to inbreeding risk, competition, and spatiotemporal variability in breeding habitat quality (Hamilton and May 1977; McPeek and Holt 1992; reviewed in Bowler and Benton 2005). However, dispersal entails 
costs (reviewed in Bonte et al. 2012) such as energetic expenditure, time spent in prospection or transfer, predation or damage risk, and opportunity costs of choosing another breeding site (e.g., loss of familiarity-including dominance on a territory).

These costs and benefits of dispersal may also depend on individual characteristics (Bowler and Benton 2005; Bonte et al. 2012). Higher natal than breeding dispersal and sexbiased dispersal can be favoured through kin competition or inbreeding avoidance (Greenwood 1980; Perrin and Mazalov 2000). Proximate explanations for decreased dispersal propensity with age are generally an increase in competitiveness or advantages from territory ownership with age and experience (Greenwood 1980; Bowler and Benton 2005; Piper 2011). Proximate explanations for sex-biased dispersal are generally mating system characteristics: one sex being more involved in the acquisition and maintenance of a territory (e.g., males in most birds; females in most mammals: Greenwood 1980; Trochet et al. 2016). Accordingly, the territorial sex benefits more from remaining in the same familiar location than from dispersing, while the other sex benefits more from dispersing to search for other mating opportunities (and to avoid kin competition and inbreeding).

To date, most recruitment and dispersal studies have focused on species that evolved in relatively stable environments in which breeding patch quality does not vary much over the timescale of an individual's life. Such environments provide sufficient habitat predictability to promote fidelity to breeding patches and year-to-year territory ownership within the patch (e.g., over many taxa, and theoretical model: Switzer 1993; in birds: McNicholl 1975; Acker et al. 2017; in mammals: Lurz et al. 1997). This context often including some spatiotemporal heterogeneity of the environment-entails harsh competition for acquiring and maintaining ownership on a high-quality territory (e.g., in birds and mammals: Cadiou et al. 1994; Kokko et al. 2004; Vanpé et al. 2009; Stockley and Bro-Jørgensen 2011). This is a major constraint inducing asymmetry in costs of dispersal or recruitment, which drives the sex-and age-dependent variations exposed above.

In contrast, such cost asymmetry may be relaxed when there is no advantage in breeding on the same patch over the years: that is, in unstable, ephemeral environments where year-to-year predictability of habitat quality is weak, such as temporary wetlands (McNicholl 1975; Béchet et al. 2012) or (semi-)arid regions (Dean 1997). High dispersal propensity is then expected (Travis and Dytham 1999; Friedenberg 2003) with the possible evolution of 'nomadic breeding' patterns (mostly described in birds; e.g., in Greenwood and Harvey 1982; Crawford et al. 1994).

Here, we assessed the extent of individual variation in dispersal and recruitment in a colonial bird with a nomadic breeding strategy. In avian colonial species, breeding terri-tories are reduced to the nest site and separated from undefended foraging resources (Evans et al. 2015). These territories are still heterogeneous in quality, due to, e.g., predation risk or parasite infestation (Boulinier and Lemel 1996). The most dispersal-prone species are typically found breeding in unstable habitats such as islets or banks in lagoons and rivers where droughts or floods frequently occur (McNicholl 1975; Oro et al. 2011). We focused on such a species, the slender-billed gull (Chroicocephalus genei) and analyzed the life histories of 3479 individuals (2392 genetically sexed, 1289 males and 1103 females) over 13 years along the French Mediterranean coast. We used multievent capture-recapture models taking breeding status uncertainty into account (Pradel 2005) to investigate the effect of breeding status (pre-breeder or breeder), age, and sex on dispersal and recruitment at a regional scale (i.e., over all colonies of the study area).

In nomadic breeders, including slender-billed gulls, the costs of dispersal and early recruitment associated with competitiveness or local familiarity for territory maintenance over the years should be largely relaxed. Though individuals still have to obtain a mate and breeding territory, ownership is not maintained over the years: territories do not bear any long-standing value (see Piper 2011). Furthermore, breeding nomadism should induce low risk of kin competition and inbreeding. Assuming that competition for holding a breeding territory over the years has, indeed, a prevailing

role in individual variations in dispersal and recruitment as emphasized above, we expected (H1) age or sex differences in dispersal propensity to be attenuated and, perhaps, absent (see Greenwood and Harvey 1982). We further expected (H2) low recruitment delays and low variation in recruitment age, and potentially (H3) sex-biased recruitment driven by asymmetry in costs of reproduction rather than by asymmetry in costs of territoriality. In the slender-billed gull, which is monogamous with biparental care (Besnard 2001), females might recruit later due to the costs of egg production that would not be compensated for in males by territoriality costs.

\section{Materials and methods Study area and species}

The slender-billed gull distribution extends from Western India to Senegal, the Caspian, Black, and Mediterranean Seas (del Hoyo et al. 2014). In the Western Mediterranean, strong immigration and emigration drive population dynamics and generate substantial variations in annual breeding numbers (Doxa et al. 2013; Sanz-Aguilar et al. 2014). Slender-billed gulls breed on isolated islands in temporary wetlands, brackish lagoons, and saltpans. Just after hatching, chicks leave the nest to join a crèche, a behaviour considered to be an adaptation to water-level unpredictability throughout the breeding season (Besnard et al. 2002). Because chick rearing occurs in crèches and nests are closely packed (Fasola and Canova 1992), 
heterogeneity in nest-territory quality is reduced to a simple risk gradient from the edge to the core of the nesting area during incubation (e.g., due to predation: Brunton 1997).

From 1998 to 2010, exhaustive survey of the French Mediterranean coast allowed locating all slender-billed gull colonies. We defined a 'colony' as the group of breeding gulls at a single island site in a given year. Over 1998-2010, 2-10 colony sites were occupied each year. A total of 60 colonies were recorded on 45 different sites (Fig. 1), with a high colony-site turnover rate (i.e., between-years change in occupied sites resulting from establishment or desertion; Erwin et al. 1981) of 0.82 (Online Appendix S1). Because almost all colony sites were abandoned from 1 year to the next, it was impracticable to consider individual variation in site-specific dispersal rates. We thus combined all colonies as a single breeding location to explore recruitment and dispersal in and out of the study area. Annual breeding population size in the area varied over 209877 pairs and reproductive success varied over 0.11-1.26 fledged chicks per nest (average: 0.72; Online Appendix S1: Fig. S1; Doxa et al. 2013).

\section{Data collection}

From 1997 onward, more than 90\% of slender-billed gulls born in France have been marked just before fledging with rings bearing an alphanumeric code (easily readable with a telescope up to $100 \mathrm{~m}$; Doxa et al. 2013). To date, the oldest bird in our data set is 20 years old (the age of the ringing-resighting programme), but slender-billed gulls can probably live even longer as do larids of similar size (oldest recorded individuals are usually ca. 30 years old: Fransson et al. 2010; and see Table 1). Sex was genetically determined from a down or feather sample using standard molecular techniques (Griffiths et al. 1998). Resightings including behavioural observations were conducted from blinds at each colony every day during several hours from arrival to departure of the birds. Apart from one colony in 2003, each colony was intensively monitored. An individual may have been resighted several times per season, but all these observations were collapsed into a single annual resighting. To build capture-recapture histories, resightings were coded as a function of behavioural observations providing the highest level of information on breeding status (see below).

\section{Modelling}

We used multievent capture-recapture models (Pradel 2005) to investigate recruitment to the study area and dispersal through temporary emigration (i.e., dispersal was modelled as the probability of leaving and coming back to the study area where ringing and resighting occurred; Schaub et al. 2004; Fig. 2, Online Appendix S2).

Each year, an individual was distinguished as being in one of the following states: (a) pre-breeder (individual that has not yet reproduced) inside the study area, (b) pre-breeder outside the area, (c) breeder inside the area, (d) breeder outside the area, or (e) dead or permanently emigrated. We then sequenced the inter-annual transition between states into three successive steps (i.e., transition probability was expressed as a product of conditional probabilities) following the natural order of post-breeding census: (i) local survival, (ii) movement (i.e., temporary emigration), and (iii) local recruitment (Fig. 2).

Multievent models allow dealing with imperfect detection and uncertainty in breeding state assessment during field observation (Pradel 2005). Within this framework, individual states are not directly observed but can be inferred from observation events (Fig. 2). Each annual occasion in an individual's capture-recapture history was coded as one of five possible observation events, reflecting to some extent its underlying breeding status (breeding or non-breeding): (i) 'not resighted', (ii) 'certain non-breeder' (only fledglings at ringing), (iii) 'uncertain breeder' (individuals observed alive but without any expected breeding behaviour), (iv) 'possible breeder' (individuals either manipulating nest material, attempting copulation, begging to, being fed by, or feeding another adult, or being begged by or accompanying a chick), and (v) 'certain breeder' (individuals incubating, replacing its partner at the nest or feeding a chick) (see Fig. 2). For each individual state, the probability of each observation event was modelled as a product of conditional probabilities: detection (i.e., resighting probability) and assignment (i.e., probability of being assigned to one of the four categories regarding breeding status assessment; Fig. 2) 


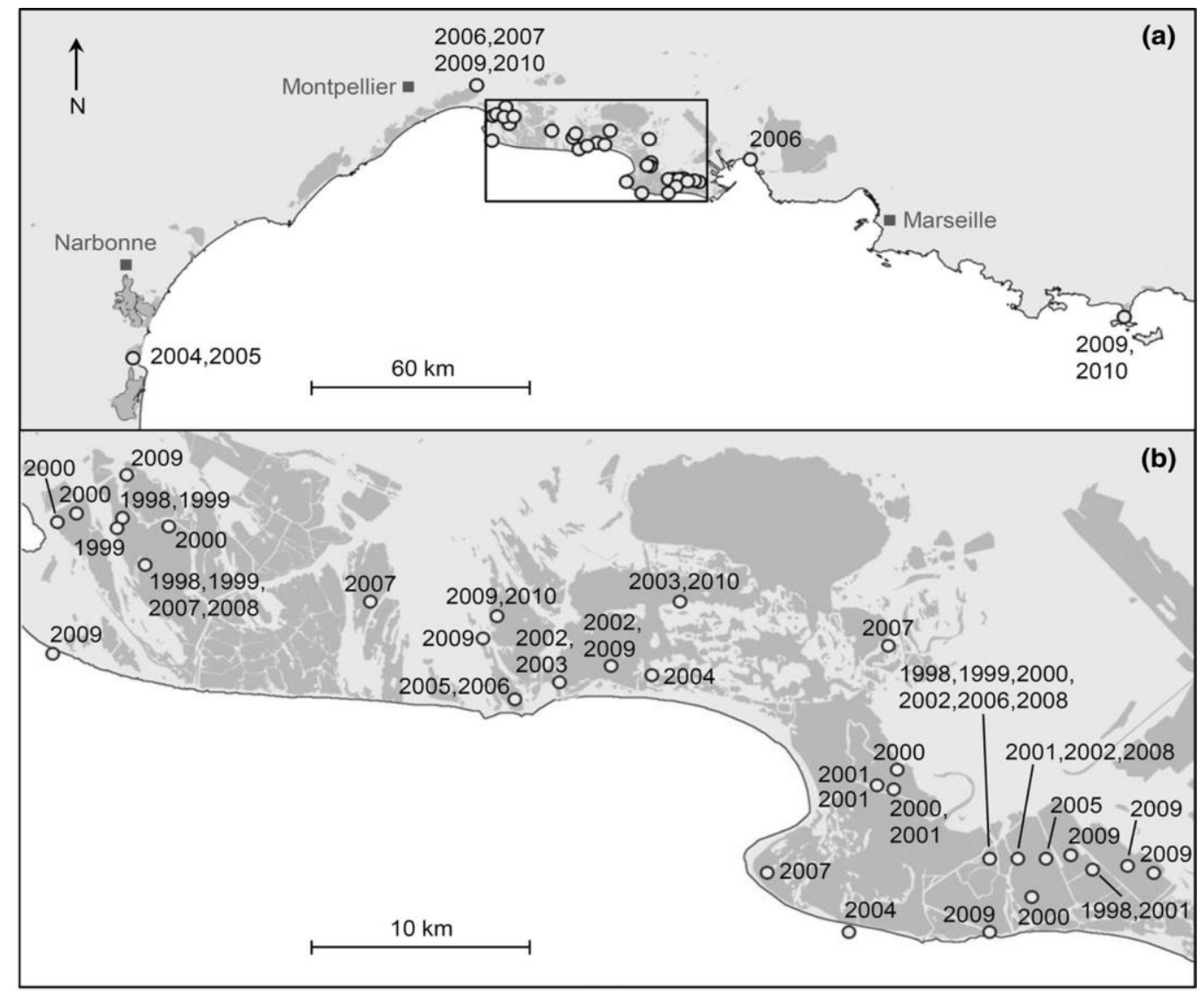

Figure 1Locations of slender-billed gull colonies in France over 1997-2012. Panel b is a zoom of the box in panel a: the Camargue wetlands. Shaded zones: marshes, white zone: Mediterranean Sea, squares: main cities. Colony sites (circles) are labelled with years of occupation. Scaling made several sites undistinguishable, which explains why less than 45 sites appear here and why the same year sometimes appears more than once next to a point

All capture-recapture histories started when the chick was ringed in the study area. To cope with identifiability issues due to the absence of resightings outside the study area (Schaub et al. 2004), we considered that an individual had equal chances of local survival in step (i) whatever its location during the breeding season. In step (ii), an individual may stay in, emigrate from, stay outside or immigrate to the study area, depending on its previous location. In step (iii), pre-breeders may become breeders from age 2 (no individual in this species was ever observed breeding before that age). They could only recruit locally or remain pre-breeder (i.e., recruitment outside the study area was not modelled). Once recruited, individuals remain in the breeder state (i.e., reproductive skipping was not modelled: we assumed that already recruited individuals breeding or skipping the breeding attempt make similar decisions concerning attendance of breeding grounds inside or outside the area).

\section{Goodness of fit}

Because goodness-of-fit tests are currently not available for multievent capture-recapture models, we tested the goodness of fit of the Cormack-Jolly-Seber model (i.e., full-time dependence on survival and detection probability without multiple states and events; Pradel et al. 2005) to our data using U-CARE v2.3.2 (Choquet et al. 2009a; Online Appendix S3). As in the previous analyses (Doxa et al. 2013), we found strong heterogeneity that may be due to transience (if local survival is agedependent; Pradel et al. 2005) and nonrandom temporary emigration (if the probability of being inside or outside the study area depends on the previous location; Schaub et al. 2004). The disparities from the Cormack-Jolly-Seber hypotheses were handled using at least two age classes (first year and second year of life) in survival and temporary emigration parameters (Pradel et al. 2005; Schaub et al. 2004; Online Appendix S2, S3). Furthermore, there was no reason for heterogeneity in detection probability. Indeed, resighting is very easy: there is no obstructing vegetation, individuals hang at the periphery of the colony when they do not incubate, and birds are very active around the crèche. 


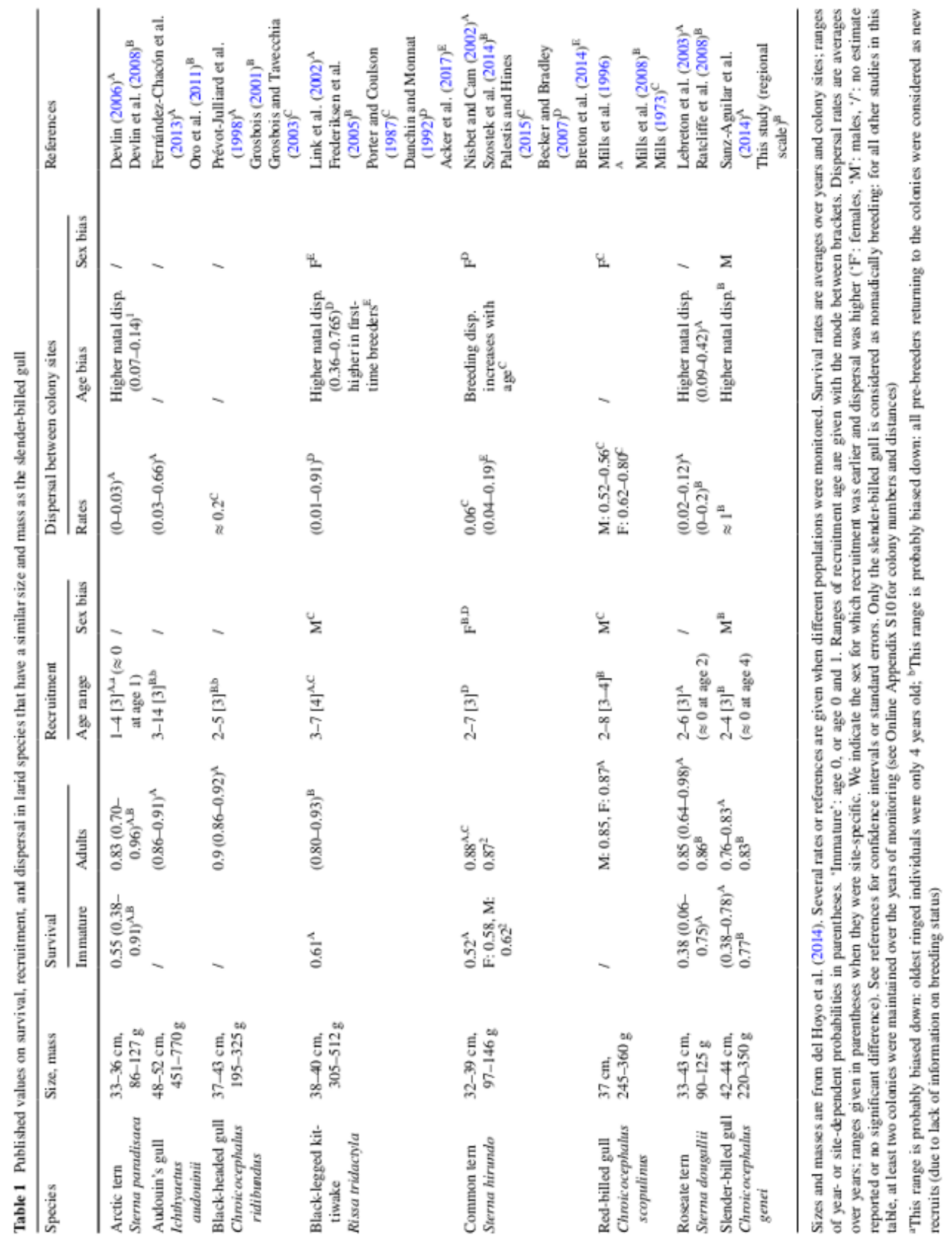




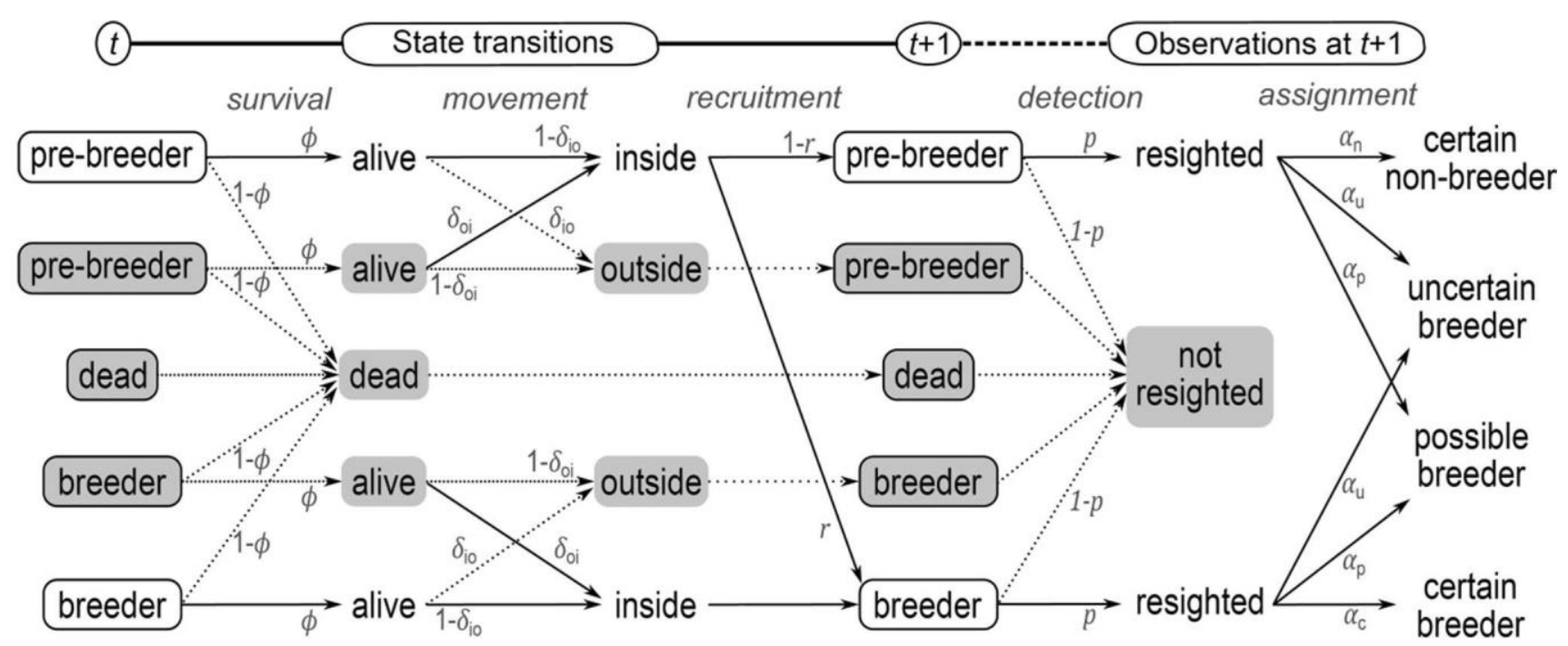

Figure 2 Diagram of fates from one breeding season $(t)$ to the next $(t+1)$. Grey boxes: unobservable states (dead or outside the study area); white boxes: observable states (inside the area). Dotted arrows: (portions of) paths leading to absence of resighting; filled arrows: paths leading to assignment of a category of assessed breeding status. Arrow subscripts specify the associated probability (if none, probability is 1): survival rate $(\phi)$, emigration rate (Sio), immigration rate (Soi), recruitment rate $(r)$, detection probability (p), assignment probability (ae, with ' $e$ ' the observation event). Newborns are only observed as 'certain non-breeder'; older individuals are no longer observed as such. Pre-breeders cannot be observed as 'certain breeder' (they have no behaviour relatable to breeding with certainty.

One might question whether dispersal decisions are taken by groups of individuals from the same colony and how it could bias dispersal estimates. This issue remains unconsidered in the literature and falls beyond the scope of our paper. Nonetheless, a bias might exist if groups are assorted according to a variable of interest. Obviously, no colony is assorted by sex or breeding status. Colonies might be assorted by age, but this effect is probably diluted among the many cohorts and colonies constituting the data set. Further, analyses of dyadic associations in this data set suggest low group tenacity (Francesiaz et al. 2017).

\section{Inference and model selection}

Analyses were conducted using E-SURGE v1.8.19 (Choquet et al. 2009b). Model selection relied on the corrected Akaike Information Criterion (AICc; Johnson and Omland 2004). We considered the best model being the one with the lowest AICc. When there were nested models with AICc differing by less than 2 units, we selected the one with the lowest number of parameters to be as conservative as possible (Burnham and Anderson 2002). Model building followed a step-wise approach. First, we conducted the analyses on the complete data set (3479 individuals) to select the best timeconstant model with agedependence, taking advantage of the largest data set as possible. This was done by reducing possible variations first on survival, and then on dispersal, recruitment, and finally on detection. Then, we conducted analyses on a reduced data set containing only individuals of known sex (2392 individuals, 1289 males and 1103 females): we fitted the model previously selected and started from this to select sex effects. The complete list of models is given in Online Appendix S4. At each step of model selection, we also selected time-varying models to check whether or not temporal variations revealed major differences that would have called into question the results from the timeconstant models (see Online Appendix S5).

When analyzing the complete data set, depending on the model, we considered 2-4 age classes in survival rates (e.g., two classes: age 1, >age 2; three classes: age 1, age 2, and >age 3), 2-4 age classes in dispersal (which also depends on individual breeding state; see above) and 1-5 age classes in recruitment (excluding yearlings which do not recruit). Numbers of age classes were chosen following conclusions from goodness-of-fit tests (see above; Online Appendix S3), prior analyses (Doxa et al. 2013) and findings in larids of similar size (Table 1). We first assumed equal detection for pre-breeders and breeders (age-dependent temporary emigration accounts for the absence of yearlings from the study area — often observed in larids; e.g., Aubry et al. 2009, Szostek et al. 2014). We tested for different detection probabilities in pre-breeders and 
breeders over a subset of best models (Online Appendix S4), because they could have differences in colony attendance inducing differences in detection. When analyzing the reduced data set (sexed individuals), we compared multiple models and considered additive or multiplicative effects of sex on biologically relevant groupings of age classes (Online Appendix S4).

\section{Results}

All AICc values and comparisons are given in Online Appendix S4. Parameter estimates from the best models in each selection step are given in Online Appendix S5, S6. Time-varying models indicated strong temporal variations in survival and movement, but not in recruitment probability. However, they provided the same conclusions on age- and sex-dependence. For clarity, we thus only present results from time-constant models (see Online Appendix S5 for time-varying models). Parameter estimates are given with $95 \%$ confidence intervals ('95\% CI').

\section{Complete data set (sexed and unsexed individuals)}

The best model without time variation (Model 1, Table 2) had two age classes for survival, four for dispersal, and three for recruitment. This model had AICc lower by 183.7 compared to the model with the minimum numbers of age classes (two age classes for survival and dispersal, one for recruitment: see "Materials and methods"; Model 101, Online Appendix S4: Table S1). Detection was independent of breeding status.

Dispersal propensity decreased with age, and breeders (i.e., already recruited in the study area) were much more philopatric than pre-breeders. The emigration probability of pre-breeders was very high at age 1 but then decreased until age 3 (Fig. 3a). Pre-breeder immigration probability was low and continuously decreased from age 2 to 4 and older (Fig. 3b). Accordingly, pre-breeders present in the area but not recruiting at age 3 were very likely to leave and came back only in small numbers sometimes many years after their emigration. For pre-breeders that survived, the probability of being inside the study area (see Online Appendix S7) increased from 0.13 to 0.39 from age 2 to 4, and then fell close to zero for older individuals (Fig. 3c). The emigration rate of breeders was lower than their immigration rate (Fig. 3a, b). For breeders that survived, the probability of being inside the study area decreased with age, from 0.95 the year after recruitment to 0.79 several years afterwards (Fig. 3c).

The bulk of recruitment ranged over 2-3 (mostly 3) years old (Fig. 3d). A quarter of pre-breeders alive and present in the study area at age 2 recruited at that age; this recruitment rate was much higher (ca. 0.9) at age 3, and similar at age 4 and older (Fig. 3d). These rates are conditional on being alive and inside the study area (Fig. 2): they must be integrated with dispersal to properly figure recruitment of locally born individuals (see Online Appendix S7). Given temporary emigration, the probability of being alive and recruiting in the natal area was 0.05 at age $2,0.18$ at age 3, falling to 0.004 at age 4 and continuing to decrease afterward (Fig. 3d).

First-year survival probability was higher than what is commonly found in larids of similar size (Table 1), but the estimate was fairly imprecise $[0.77(0.30,0.96)]$. Two complementary models in which we fixed first-year survival at 0.5 or 0.95 slightly modified pre-breeder dispersal probabilities (Online Appendix S6: Table S8), but other parameters were not impacted, so that our conclusions on age-dependent dispersal and recruitment remained unchanged. Detection was very high [0.86 $(0.83,0.88)]$ and assignment probabilities were consistent regarding the observer's ability to assess breeding status (see Online Appendix S8). 
Table 2 Summary of time-constant model selection

\begin{tabular}{|c|c|c|c|c|c|c|c|c|c|c|}
\hline \multirow[t]{2}{*}{ Data } & \multirow[t]{2}{*}{ Step } & \multirow[t]{2}{*}{ Covariates included } & \multirow[t]{2}{*}{ Model } & \multicolumn{4}{|c|}{ Parameter variation } & \multirow[t]{2}{*}{$K$} & \multirow[t]{2}{*}{$\triangle \mathrm{AICc}$} & \multirow[t]{2}{*}{ WAICc } \\
\hline & & & & 95 & $s$ & $r$ & $p$ & & & \\
\hline \multirow[t]{5}{*}{ I } & \multirow[t]{5}{*}{$\mathrm{i}$} & \multirow[t]{5}{*}{ Age } & 1 & $\mathrm{~A}_{1, \geq 2} \mathrm{~A}_{1, \geq}$ & $E \times \mathrm{A}_{1,2,3, \geq 4} E \times$ & $\mathrm{A}_{2,3, \geq}{ }_{4}$ & . & 19 & 0 & 0.23 \\
\hline & & & 2 & $2 \mathrm{~A}_{1, \geq 2}$ & $\mathrm{~A} 1,2,3, \geq 4 E \times$ & $\mathrm{A} 2,3,4, \geq 5$ & & 20 & 1.32 & 0.12 \\
\hline & & & 3 & $\mathrm{~A}[1,2], \geq 3$ & $\mathrm{~A}_{1,2,3, \geq 4} E$ & $\mathrm{~A} 2,3, \geq 4$ & E & 20 & 1.43 & 0.11 \\
\hline & & & 4 & $\mathrm{~A}_{1,2, \geq 3}$ & $\times \mathrm{A}_{1,2,3, \geq 4} E \times$ & $\mathrm{A}_{2,3, \geq 4}$ & . & 19 & 1.78 & 0.10 \\
\hline & & & 5 & $\mathrm{~A}_{1, \geq 2} \mathrm{~A}_{1, \geq}$ & $\mathrm{A}_{1,2,3, \geq 4} E \times$ & $\mathrm{A}_{2,3, \geq 4}$ & . & 20 & 1.99 & 0.09 \\
\hline \multirow[t]{6}{*}{ II } & ii & Age & 6 & $2 \mathrm{~A}_{1, \geq 2}$ & $\mathrm{~A}_{1,2,3, \geq 4} E \times$ & $\mathrm{A} 2,3, \geq 4$ & . & 19 & 9.49 & 0 \\
\hline & \multirow[t]{5}{*}{ iii } & \multirow[t]{5}{*}{ Age, sex } & 7 & $\mathrm{~A}_{1, \geq 2} \mathrm{~A}_{1, \geq}$ & $(\mathrm{A} 1,2,3, \geq 4+\mathrm{S}) E \times$ & $\mathrm{A}_{2,3, \geq 4}+\mathrm{A}[2: 3] \times \mathrm{S}$ & . & 21 & 0 & 0.39 \\
\hline & & & 8 & $2 \mathrm{~A}_{1, \geq 2}$ & $(\mathrm{~A} 1,2,3, \geq 4+\mathrm{S}) E \times$ & $\mathrm{A}_{2,3} \times \mathrm{S}+\mathrm{A}_{\geq}$ & . & 22 & 1.66 & 0.17 \\
\hline & & & 9 & & $\left(\mathrm{~A}_{1,2,3, \geq 4}+\mathrm{S}\right) E \times$ & $\mathrm{A} 2,3, \geq 4+\mathrm{S}$ & . & 21 & 2.57 & 0.11 \\
\hline & & & 10 & & $(\mathrm{~A} 1,2,3, \geq 4+\mathrm{S}) E \times$ & $\mathrm{A}_{2,3, \geq 4} \times \mathrm{S}$ & . & 23 & 3.05 & 0.08 \\
\hline & & & 11 & & $\left(\mathrm{~A}_{1,2,3, \geq 4}+\mathrm{S}\right)$ & $\mathrm{A}_{2, \geq 4}+\mathrm{A}_{3} \times \mathrm{S}$ & . & 21 & 3.61 & 0.06 \\
\hline
\end{tabular}

Only the five best models in each selection step are given. This summary indicates how survival (q5), movement (S), local recruitment ( $r$ ), and detection $(p)$ probabilities vary with the covariates considered $(A$ age; $S$ sex) and individual states $(E$ pre-breeder inside the area, pre-breeder outside the area, breeder inside the area and breeder outside the area). '?' indicates no variation. With the complete data set (I), 73 models were compared (step i). With the reduced data set (II, only sexed individuals), 40 models were compared: we first (step ii) fitted the best age-dependent structure selected in step i (Model 1), then (step iii) selected the best sex-dependent model. ' $x$ ' designates interactions, ' + ' designates additive effects. Subscripts specify age-class divisions and combinations. $K$ is the number of parameters, $\Delta$ AICc is the difference in corrected Akaike Information Criterion to the best model for each data set, wAICc is the corresponding AICc weights. Parameter estimates from model 1, 6, and 7 are given in Online Appendix S6: Table 7

\section{Reduced data set (sexed individuals)}

In the time-constant model applied to the reduced data set (Model 6, Table 2), estimates were very similar to what was previously obtained (Model 1), with larger confidence inter-vals (Online Appendix S6: Table S7). First-year survival probability was very poorly estimated $[0.997(0,1)]$. In a complementary model with the first-year survival fixed at 0.77 (value from Model 1), estimates were even more similar to Model 1 (Online Appendix S6: Table S8).

Males recruited later and dispersed slightly more than females (Model 6 vs. Model 7, AICc difference: 9.49, Table 2). The best models showed no sex bias in survival. There was a sex difference in movement probability, which was irrespective of movement direction [emigration or immigration; estimate of the difference had 95\% CI excluding zero: 0.19 $(0.02,0.36)$ on the logit scale]. Movement probability was slightly higher for males [e.g., pre-breeder emigration at age 1 was $0.88(0.86,0.89)$ for males and $0.85(0.83,0.87)$ for females; Online Appendix S6]. There was also a sex difference in recruitment probability at age 2 and 3 [estimate of the difference had $95 \%$ CI excluding zero: $0.88(0.27,1.50)$ on the logit scale]. Local recruitment probability was higher for males [at age 2: $0.31(0.22,0.42)$, at age 3: $0.92(0.84,0.96)]$ than for females [at age 2: $0.16(0.10,0.25)$, at age $3: 0.83(0.72,0.90)]$. 


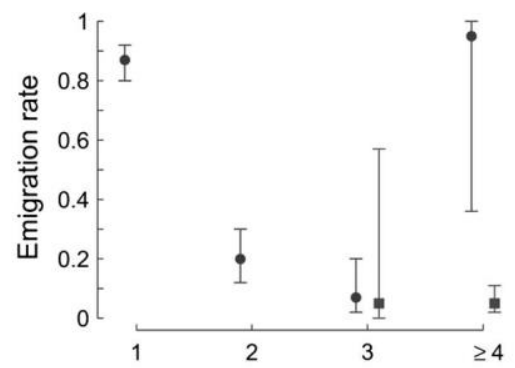

(a)

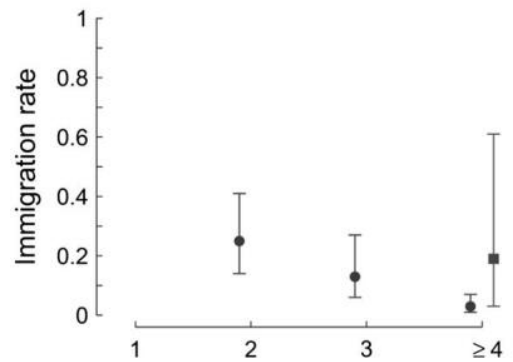

(b)

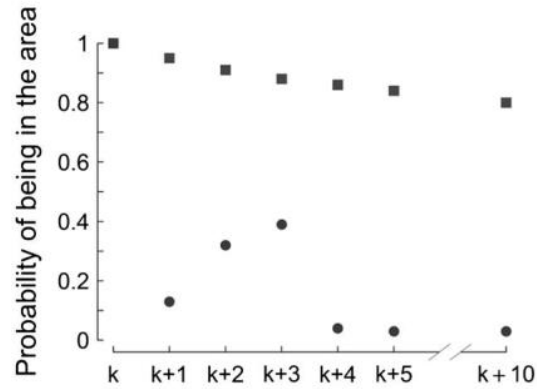

(c)

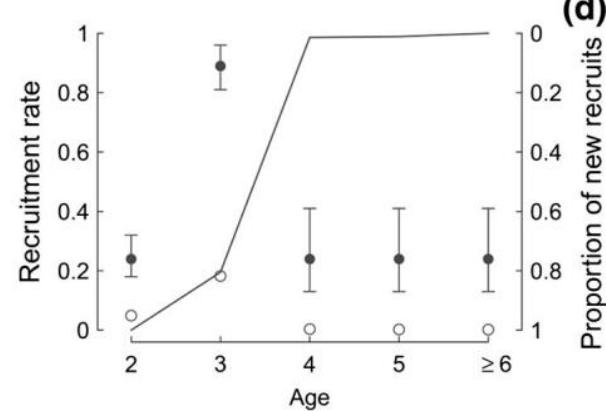

Figure 3 Age-dependent a emigration, b immigration, c presence in the study area, and d recruitment. Circles: pre-breeders; squares: breeders. Individual histories start at birth in the study area: pre-breeder emigration occurs only from age 1, prebreeder immigration from age 4 . In panel $c$, ' $k$ ': age 0 for pre-breeders and recruitment age for breeders. In panel d, filled circles: recruitment rate conditional on being alive in the study are (i.e., parameter in the model), open circles: recruitment rate for any locally born individual (not conditional on being alive in the area), line: proportion of new recruits among alive breeders (in or out the study area). Segments indicate 95\% confidence intervals. Parameter estimates are from Model 1 (Online Appendix S6: Table S7), from which probabilities of being in the study area were derived (Online Appendix S7)

\section{Discussion}

Because the slender-billed gull is socially and seasonally monogamous, and nomadically breeding, we suggested that the lack of breeding site tenacity and year-to-year territory ownership might induce no difference in dispersal according to age or sex (H1), and a limited delay in recruitment age $(\mathrm{H} 2)$ with females recruiting later than males (H3). Our results are in accordance with these predictions: (H2) recruitment presented low delay and (H3) males recruited earlier than females. In contrast (with H1), we found that temporary emigration was higher in pre-breeders than in breeders and decreased with age, and males had a slightly higher tendency to disperse outside the study area than females. These results suggest that other mechanisms than those associated with competition for holding a breeding territory over the years shape betweenindividual variations in dispersal and recruitment. 
Age at first reproduction is commonly quite variable in long-lived species occupying relatively stable habitats. In these species, few individuals recruit early and recruitment is spread over several age classes (e.g., Becker and Bradley 2007; Kim et al. 2011; Martin and Festa-Bianchet 2012; Desprez et al. 2014). In colonial larids that have about the same size and lifespan as the slender-billed gull, reproduction can begin at age 2, but most recruitment occurs at age 3-6 and may spread even later (Table 1). In the slenderbilled gull, recruitment in the natal area occurs earlier and shows a much narrower spread over age classes (very few recruitment at age 2, most at age 3, and almost no at older ages).

In relatively stable habitats, year-to-year colony-site tenacity strengthens the importance of nest-site differences, which implies prospecting, contesting, and eventually queuing for good-quality habitats; a competitive process that may expand over several years (Becker and Bradley 2007; van de Pol et al. 2007; Aubry et al. 2009). Nomadic breeders are not constrained by such long-standing competition, which may explain the lower recruitment delays in slender-billed gulls (compared to other species, Table 1). Alternatively, the apparent larger recruitment delays in species in stable habitats might result from the relatively small spatial scale of most studies (one or a few close colonies), whereas we studied recruitment at a regional scale spanning over several hundred kilometres. For instance, in a metapopulation of black-headed gulls, recruitment in the largest colony (probably saturated but of high quality) occurred later (age 2-5) than in smaller colonies (probably less competitive but of lower quality: age 2-4; Grosbois 2001). Accordingly, if one ignores small patches and focuses only on large, saturated patches where competition for territories is stronger, recruitment age is likely to be overestimated.

A decrease in breeding density may thus enhance accessibility to breeding sites, therefore, anticipating recruitment (see, e.g., Crespin et al. 2006). Density dependence is unlikely to operate in the slender-billed gull in our study area: observations do not suggest that nesting space is limiting in the colony sites, and breeding pairs on a colony site are usually 100-300 (maximum observed: 722) which is low compared to ca. 6000 pairs in Sfax, Tunisia (Sanz-Aguilar et al. 2014). The absence of year-to-year territory ownership and the low heterogeneity in nest-site quality within the colony clearly relax the competition for nest sites. This is also suggested by the low levels of aggression in crèching larids inhabiting unstable habitats compared with non crèching larids in relatively stable habitats (Besnard et al. 2006). The remaining variability in recruitment age which we detected might stem from slight individual differences in behavioural maturation (e.g., gain in competitive and foraging skills), mating, and synchronization with the group (Aubry et al. 2009), which can be expected in most animal taxa (Charlesworth 1994).

Moreover, we modelled recruitment only inside the study area in locally born individuals. It is, however, likely that part of recruitment occurs outside this area, so that actual recruitment might be even less delayed than what our results indicate. This would be in line with findings in the Audouin's gull (Ichthyaetus audouinii), another larid thought to have evolved in unstable habitats. In this species, Oro et al. (2011) showed no difference in recruitment rates between immigrants and native individuals in the largest colony. Similarly, recruitment rates of slender-billed gulls might be identical in the natal or immigration area.

\section{Breeding status and age-dependence in dispersal}

Yearlings were very likely to be outside the study area, corroborating the fact that immature larids are usually absent from the breeding grounds (e.g., Aubry et al. 2009, Szostek et al. 2014). In addition, and even when excluding yearlings, temporary emigration was lower in breeders than in pre-breeders at the regional scale modelled here (Fig. 3). Breeder emigration was higher at age 3 than at age 4 and older (although this was unclear in time-constant models, it was confirmed by time-varying models; Fig. 3, Online Appendix S5). Overall, breeders were much more regionally philopatric than we expected, though they were not philopatric to the colony site. Nevertheless, permanent emigration is strongly suspected in slender-billed gulls because of the low local survival estimates (Doxa et al. 2013; and see Table 1). Such an increase in philopatry with age or experience is a usual pattern in non-nomadic larids of similar size (at the colony scale: Table 1), as well as in many animals, and can be explained by increased competitive abilities which ease territory acquisition and maintenance (Bowler and Benton 2005). Even when a habitat is unstable at the local scale, older individuals may benefit from spatial knowledge of potential foraging and breeding zones that do not radically change over the years at the regional scale (e.g., Bradshaw et al. 2004; Wakefield et al. 2015), which should favour a decrease in dispersal propensity with age. Here, this idea is also supported by the clear tendency of slender-billed gulls to use the same wetland complex in the Camargue over the years (Fig. 1).

\section{Sex bias in dispersal}

The animal literature have suggested that kin competition and inbreeding risk weakly explain which sex disperses the most (and they may be avoided through kin recognition), but territoriality has remained a major explanatory factor (Trochet et al. 2016). In bird species inhabiting relatively stable environments (or at least non-nomadic breeders), males usually disperse less than females (see, e.g., in larids: Table 1), because breeding habitat predictability provide them with benefits in holding the same territory over the years (Greenwood and Harvey 1982). In contrast, our results suggest that slender-billed gull males moved in and out of the 
study area slightly more often than did females. Even if the difference was small as expected, it was significant and deserves attention.

Interestingly, in slender-billed gull fledglings, the sex ratio at ringing was slightly imbalanced [46\% females out of 2392 sexed individuals $\left(\mathrm{X}^{2}=14.32, P<0.001\right)$ over the study period, with the same trend in most years: Online Appendix S9]. As we detected no sex effect on survival, this bias should persist in all age classes. In most animal taxa, lower availability of females is expected to strengthen male-male competition for mating (Jirotkul 1999), thus promoting female choosiness (Berglund 1994), a behaviour known to favour male dispersal (Kokko and Rankin 2006). In addition, higher regional philopatry could offer females a familiarity advantage (Piper 2011) in acquiring feeding experience in the area (e.g., Bradshaw et al. 2004), especially in regard to investment in egg laying (Williams 2005; and see below). More generally in animal taxa, a similar reasoning could be applied to explain sex-biased dispersal, based on asymmetry in the costs induced by parental investment or even secondary sexual traits (Trochet et al. 2016).

\section{Sex bias in recruitment}

We predicted later female recruitment due to costs of egg laying which would not be (over)compensated by costs of holding a breeding territory over the years for males. In non nomadic larids having a similar size as the slender-billed gull, both male and female biases have been reported in recruitment age (Table 1). Although rarely documented in the animal literature, sexbiased recruitment has been suggested to result from unbalanced sex ratio, as the surplus of one sex strengthens intrasexual competition and reduces access to reproduction (Mills 1973; Becker and Bradley 2007). However, slender-billed gull males recruited earlier than the outnumbered females, so that competition for mating cannot drive sex-dependence in recruitment in this case. In many birds, including larids, laying date gets earlier with age and is negatively correlated with breeding success (Forslund and Pürt 1995; Arnold et al. 2004). This may stem from experience-driven improvements in performance (Bos-man et al. 2013). In slender-billed gulls, egg laying is highly synchronous, taking place within less than 15 days (Besnard 2001). Such synchronization is explained by crèching behaviour: late-born chicks are unable to join the crèche when it leaves the colony site and consequently die (Besnard 2001). This context of asymmetry in reproductive costs suggests that unsynchronized young females (that lay too late) may be prone to delaying recruitment to ensure chick survival through synchronous laying with older, experienced individuals. More generally in animal taxa, asymmetry in reproductive costs (Clutton-Brock 1991) should not be neglected among the forces that are likely to produce sex differences in recruitment patterns.

\section{Conclusion}

Our study invites to revisit recruitment and dispersal paradigms in long-lived species that were mostly elaborated from the study of species incurring territorial costs associated with year-to-year territory maintenance and notably facing competition resulting from density-dependence. Here, we showed that a nomadically breeding bird species with absence of year-to-year territory holding exhibited a few differences in dispersal between sexes and had almost no delay and variation in recruitment age. Nonetheless, remaining variations in recruitment age and state-dependent dispersal (here, a delay in female recruitment, a slight male-biased dispersal, and increased dispersal with age) suggest the role of other ecological processes such as sex ratio imbalance, asymmetric costs of reproduction, and benefits of regional familiarity.

Acknowledgements We are grateful to the many volunteers, ring-ers, and students who assisted with captures and observations at the colonies, and in particular to Christophe Pin who has been instrumental in maintaining the ring-resighting effort on the long-term. We are also grateful to Roger Pradel for his useful advice about E-SURGE and multievent modelling. The monitoring of the slender-billed gull was funded by Tour du Valat, the non-profit organisation Les Amis du Marais du Vigueirat, and the MAVA foundation. This work was supported by the French Laboratory of Excellence project 'TULIP' (ANR-10-LABX-41; ANR-11-IDEX-0002-02).

Author contribution statement PA, CF, and A Besnard formulated the ideas; PA and CF performed the analyses and wrote the manuscript; NS conceived the monitoring study. NS and A Béchet were responsible for data collection; ASP performed genetic sexing; A Besnard, A Béchet, CML, and NS provided editorial advice. PA and CF have contributed equally to the work. 


\section{References}

Acker P, Besnard A, Monnat J-Y, Cam E (2017) Breeding habitat selection across spatial scales: is grass always greener on the other side? Ecol 98: 2684-2697

Arnold JM, Hatch JJ, Nisbet IC (2004) Seasonal declines in reproductive success of the common tern Sterna hirundo: timing or parental quality? J Avian Biol 35:33-45

Aubry LM, Cam E, Monnat J-Y (2009) Habitat selection, age-specific recruitment and reproductive success in a long-lived seabird. In: Thomson DL, Cooch EG, Conroy MJ (eds) Modeling demographic processes in marked populations. Springer, New York, pp 365-392

Béchet A, Rendón-Martos M, Rendón MA, Amat JA, Johnson A, Gauthier-Clerc M (2012) Global economy interacts with climate change to jeopardize species conservation: the case of the greater flamingo in the Mediterranean and West Africa. Envir Conser 39:1-3

Becker PH, Bradley JS (2007) The role of intrinsic factors for the recruitment process in long-lived birds. J Ornithol 148:377-384 Berglund A (1994) The operational sex ratio influences choosiness in a pipefish. Behav Ecol 5:254-258

Besnard A (2001) Evolution de l'élevage des poussins en crèche chez les laridés. PhD dissertation, Université de Montpellier 2, France

Besnard A, Gimenez O, Lebreton J-D (2002) A model for the evolution of crèching behaviour in gulls. Evol Ecol 16:489-503

Besnard A, Sadoul N, Lebreton J-D (2006) First quantitative comparison of aggression between crèching and non-crèching larid species. Waterbirds 29:481-488

Bonte D, Van Dyck H, Bullock JM, Coulon A, Delgado MM et al (2012) Costs of dispersal. Biol Rev 87:290-312

Bosman DS, Vercruijsse HJ, Stienen EW, Vincx M, Lens L (2013) Age of first breeding interacts with pre-and post-recruitment experience in shaping breeding phenology in a long-lived gull. PLoS ONE 8:e82093

Boulinier T, Danchin E (1997) The use of conspecific reproductive success for breeding patch selection in terrestrial migratory species. Evol Ecol 11:505-517

Boulinier T, Lemel J-Y (1996) Spatial and temporal variation of factors affecting breeding habitat quality in colonial birds: some consequences for dispersal and habitat selection. Acta Oecol 17:531-552

Bowler DE, Benton TG (2005) Causes and consequences of animal dispersal strategies: relating individual behaviour to spatial dynamics. Biol Rev 80:205-225

Bradshaw CJA, Hindell MA, Sumner MD, Michael KJ (2004) Loyalty pays: potential life history consequences of fidelity to marine foraging regions by southern elephant seals. Anim Behav 68:1349-1360

Breton AR, Nisbet ICT, Mostello CS, Hatch JJ (2014) Age-dependent breeding dispersal and adult survival within a metapopulation of common terns sterna hirundo. Ibis 156:534-547

Brunton DH (1997) Impacts of predators: center nests are less successful than edge nests in a large nesting colony of Least Terns. Condor 99:372-380

Burnham KP, Anderson DA (2002) Model selection and multimodel inference: a practical information-theoretic approach. Springer, New York

Cadiou B, Monnat J-Y, Danchin E (1994) Prospecting in the kittiwake, Rissa tridactyla: different behavioral patterns and the role of squatting in recruitment. Anim Behav 47:847-856

Cam E, Aubry L (2011) Early development, recruitment and life history trajectory in long-lived birds. J Ornithol 152:187-201

Charlesworth B (1994) Evolution in age-structured populations. Cambridge University Press, Cambridge

Choquet R, Lebreton J-D, Gimenez O, Reboulet AM, Pradel R (2009a) U-CARE: utilities for performing goodness of fit tests and manipulating capture-recapture data. Ecography 32:1071-1074

Choquet R, Rouan L, Pradel R (2009b) Program E-Surge: a software application for fitting multievent models. In: Thomson DL, Cooch EG, Conroy MJ (eds) Modeling demographic processes in marked populations. Springer, New York, pp 845-865

Clutton-Brock TH (1991) The evolution of parental care. Princeton University Press, Princeton

Congdon JD, Dunham AE, van Loben Sels RC (1993) Delayed sexual maturity and demographics of Blanding's Turtles (Emydoidea blandingii): implications for conservation and management of long-lived organisms. Conserv Biol 7:826-833

Crawford RJM, Dyer BM, Brooke RK (1994) Breeding nomadism in southern African seabirds-constraints, causes and conservation. Ostrich 65:231-246

Crespin L, Harris MP, Lebreton JD, Frederiksen M, Wanless S (2006) Recruitment to a seabird population depends on environmental factors and on population size. J Anim Ecol 75:228-238

Danchin E, Monnat J-Y (1992) Population-dynamics modeling of two neighboring kittiwake rissa-tridactyla colonies. Ardea 80:170-180

Dean W (1997) The distribution and biology of nomadic birds in the Karoo, South Africa. J Biogeogr 24:769-779

del Hoyo J, Elliott A, Sargatal J (2014) Handbook of the birds of the world. Lynx, Barcelona

Desprez M, Harcourt R, Hindell MA, Cubaynes S, Gimenez O, McMahon CR (2014) Age-specific cost of first reproduction in female southern elephant seals. Biol Lett 10:20140264

Devlin CM (2006) Birds crossing borders: a population study of arctic terns (Sterna paradisaea). PhD dissertation, University of New Brunswick, USA

Devlin CM, Diamond AW, Kress SW et al (2008) Breeding dispersal and survival of Arctic Terns (Sterna Paradisaea) nesting in the Gulf of Maine. Auk 125:850-858

Doxa A, Besnard A, Bechet A, Pin C, Lebreton J-D, Sadoul N (2013) Inferring dispersal dynamics from local population demographic modelling: the case of the slender-billed gull in France. Anim Conserv 16:648-693

Ens BJ, Weissing FJ, Drent RH (1995) The despotic distribution and deferred maturity: two sides of the same coin. Am Nat 146:625-650

Erwin RM, Galli J, Burger J (1981) Colony site dynamics and habitat use in Atlantic coast seabirds. Auk 98:550-561

Evans JC, Votier SC, Dall SRX (2015) Information use in colonial living. Biol Rev 91:658-672

Fasola M, Canova L (1992) Nest habitat selection by eight synoptic species of Mediterranean Gulls and Terns. Colon Waterbirds 15:169-178

Fernàndez-Chacón A, Genovart M, Pradel R et al (2013) When to stay, when to disperse and where to go: survival and dispersal patterns in a spatially structured seabird population. Ecography $36: 1117-1126$

Forslund P, Pärt T (1995) Age and reproduction in birds—hypotheses and tests. Trends Ecol Evol 10:374-378

Francesiaz C, Farine D, Laforge C, Béchet A, Sadoul N, Besnard A (2017) Familiarity drives social philopatry in an obligate colonial 
breeder with weak interannual breeding-site fidelity. Anim Behav 124:125-133

Fransson T, Kolehmainen T, Kroon C, Jansson L, Wenninger T (2010) EURING list of longevity records for European birds. https://euring.org/data and codes/longevity.htm. Accessed 13 Oct 2017

Frederiksen M, Harris MP, Wanless S (2005) Inter-population variation in demographic parameters: a neglected subject? Oikos 111:209-214

Friedenberg NA (2003) Experimental evolution of dispersal in spatiotemporally variable microcosms. Ecol Lett 6:953-959

Gaillard J-M, Festa-Bianchet M, Yoccoz NG et al (2000) Temporal variation in fitness components and population dynamics of large herbivores. Annu Rev Ecol Evol Sys 31(1):367-393

Greenwood PJ (1980) Mating systems, philopatry and dispersal in birds and mammals. Anim Behav 28:1140-1162

Greenwood PJ, Harvey PH (1982) The natal and breeding dispersal of birds. Annu Rev Ecol Evol Syst 13:1-21

Griffiths R, Double MC, Orr K, Dawson RJG (1998) A DNA test to sex most birds. Mol Ecol 7:1071-1075

Grosbois, V (2001) La dispersion: trait d'histoire de vie et paramètre démographique: étude empirique dans une population de mouette rieuse. PhD dissertation, Université de Montpellier 2, France

Grosbois V, Tavecchia G (2003) Modeling dispersal with capturerecapture data: disentangling decisions of leaving and settlement. Ecology $84: 1225-1236$

Hamilton WD, May RM (1977) Dispersal in stable habitats. Nature 269:578-581

Jirotkul M (1999) Operational sex ratio influences female preference and male-male competition in guppies. Anim Behav 58:287-294 Johnson JB, Omland KS (2004) Model selection in ecology and evolution. Trends Ecol Evol 19:101-108

Kim S-Y, Velando A, Torres R, Drummond H (2011) Effects of recruiting age on senescence, lifespan and lifetime reproductive success in a long-lived seabird. 166:615-626

Kokko H, Rankin DJ (2006) Lonely hearts or sex in the city? Density-dependent effects in mating systems. Philos Trans R Soc B 361:319-334

Kokko H, Harris MP, Wanless S (2004) Competition for breeding sites and site-dependent population regulation in a highly colonial seabird, the common guillemot Uria aalge. J Anim Ecol 73:367-376

Komers PE, Pélabon C, Stenström D (1997) Age at first reproduction in male fallow deer: age-specific versus dominance-specific behaviors. Behav Ecol 8:456-462

Lebreton JD, Hines JE, Pradel R, Nichols JD, Spendelow JA (2003) Estimation by capture-recapture of recruitment and dispersal over several sites. Oikos 101:253-264

Link WA, Cam E, Nichols JD, Cooch EG (2002) Of bugs and birds: Markov chain Monte Carlo for hierarchical modeling in wildlife research. J Wildl Manag 66:277-291

Lurz PWW, Garson PJ, Wauters LA (1997) Effects of temporal and spatial variation in habitat quality on red squirrel dispersal behaviour. Anim Behav 54:427-435

Martin JGA, Festa-Bianchet M (2012) Determinants and consequences of age of primiparity in bighorn ewes. Oikos 121:752-760

McNicholl MK (1975) Larid site tenacity and group adherence in relation to habitat. Auk 92:98-104

McPeek MA, Holt RD (1992) The evolution of dispersal in spatially and temporally varying environments. Am Nat 140:1010-1027

Michener GR, Locklear L (1990) Differential costs of reproductive effort for male and female richardson's ground squirrels. Ecology 71:855868

Mills JA (1973) The influence of age and pair-bond on the breeding biology of the red-billed gull Larus novaehollandiae scopulinus. J Anim Ecol 42:147-162

Mills JA, Yarrall JW, Mills DA (1996) Causes and consequences of mate fidelity in red-billed gulls. In: Black JM (ed) Partnerships in birdsthe study of monogamy. Oxford University Press, Oxford, pp 118-137

Mills JA, Yarrall JW, Bradford-Grieve JM, Uddstrom MJ, Renwick JA, Merilä J (2008) The impact of climate fluctuation on food availability and reproductive performance of the planktivorous red-billed gull Larus novaehollandiae scopulinus. J Anim Ecol 77:1129-1142

Nisbet IC, Cam E (2002) Test for age-specificity in survival of the common tern. J Appl Stat 29:65-83

Oro D, Tavecchia G, Genovart M (2011) Comparing demographic parameters for philopatric and immigrant individuals in a longlived bird adapted to unstable habitats. 165:935-945

Palestis BG, Hines JE (2015) Adult survival and breeding dispersal of common terns (Sterna hirundo) in a declining population. Waterbirds 38:221-228

Perrin N, Mazalov V (2000) Local competition, inbreeding, and the evolution of sex-biased dispersal. Am Nat 155:116-127

Piper WH (2011) Making habitat selection more "familiar": a review. Behav Ecol Sociobiol 65:1329-1351

Porter JM, Coulson JC (1987) Long-term changes in recruitment to the breeding group, and the quality of recruits at a kittiwake Rissa tridactyla colony. J Anim Ecol 56:675-689

Pradel R (2005) Multievent: an extension of multistate capturerecapture models to uncertain states. Biometrics 61:442-447

Pradel R, Gimenez O, Lebreton J-D (2005) Principles and interest of GOF tests for multistate capture-recapture models. Animal Biodivers Conserv 28:189-204

Prévot-Julliard A-C, Lebreton J-D, Pradel R (1998) Re-evaluation of adult survival of black-headed gulls (Larus ridibundus) in presence of recapture heterogeneity. Auk 115:85-95

Ratcliffe N, Newton S, Morrison P et al (2008) Adult survival and breeding dispersal of roseate terns within the northwest European metapopulation. Waterbirds 31:320-329

Sanz-Aguilar A, Tavecchia G, Afàn I, Ramírez F, Doxa A, Bertolero A, Gutiérrez-Expósito C, Forero MG, Oro D (2014) Living on the edge: demography of the slender-billed gull in the western mediterranean. PLoS ONE 9:e92674

Schaub M, Gimenez O, Schmidt BR, Pradel R (2004) Estimating survival and temporary emigration in the multistate capturerecapture framework. Ecology 85:2107-2113

Stockley P, Bro-Jørgensen J (2011) Female competition and its evolutionary consequences in mammals. Biol Rev 86:341-366 Switzer PV (1993) Site fidelity in predictable and unpredictable habitats. Evol Ecol 7:533-555

Szostek KL, Schaub M, Becker PH (2014) Immigrants are attracted by local pre-breeders and recruits in a seabird colony. J Anim Ecol 83:10151024 
Travis JMJ, Dytham C (1999) Habitat persistence, habitat availability

and the evolution of dispersal. Proc R Soc B 266:723-728 Trochet A, Courtois EA, Stevens VM et al (2016) Evolution of sexbiased dispersal. Q Rev Biol 91:297-320

van de Pol M, Pen I, Heg D, Weissing FJ (2007) Variation in habitat choice and delayed reproduction: adaptive queuing strategies or individual quality differences? Am Nat 170:530-541

Vanpé C, Gaillard J-M, Morellet N et al (2009) Age-specific variation in male breeding success of a territorial ungulate species, the European roe deer. J Mammal 90:661-665

Wakefield ED, Cleasby IR, Bearhop S et al (2015) Long-term individual foraging site fidelity—why some gannets don't change their spots. Ecology 96:3058-3074

Williams TD (2005) Mechanisms underlying the costs of egg produc

tion. Bioscience 55:39-48 